\title{
Telomerase reverse transcriptase methylation predicts lymph node metastasis and prognosis in patients with gastric cancer
}

\author{
Yongxin $\mathrm{Wu}^{1,2}$ \\ Guichao $\mathrm{Li}^{1,2}$ \\ Dong $\mathrm{He}^{3}$ \\ Fengping Yang ${ }^{3}$ \\ Guang $\mathrm{He}^{3}$ \\ Lin $\mathrm{He}^{3}$ \\ Hui Zhang ${ }^{1,2}$ \\ Yun Deng ${ }^{1,2}$ \\ Ming Fan ${ }^{1,2}$ \\ Lijun Shen ${ }^{1,2}$ \\ Daizhan Zhou ${ }^{3}$ \\ Zhen Zhang ${ }^{1,2}$ \\ 'Department of Radiation Oncology, \\ Fudan University Shanghai Cancer \\ Center, ${ }^{2}$ Department of Oncology, \\ Shanghai Medical College, Fudan \\ University, ${ }^{3}$ Bio-X Center, Key \\ Laboratory for the Genetics of \\ Developmental and Neuropsychiatric \\ Disorders (Ministry of Education), \\ Shanghai Jiao Tong University, \\ Shanghai, People's Republic of China
}

Correspondence: Zhen Zhang Department of Radiation Oncology, Fudan University Shanghai Cancer Center, 270 Dong An Road, Shanghai 200032, People's Republic of China Email zhenzhang66@I63.com

Daizhan Zhou

Bio-X Center, Key Laboratory for the Genetics of Developmental and Neuropsychiatric Disorders (Ministry of Education), Shanghai Jiao Tong University, 1954 Huashan Road, Shanghai 200030,

People's Republic of China

Email zhoudaizhan@sjtu.edu.cn
This article was published in the following Dove Press journal:

OncoTargets and Therapy

II January 2016

Number of times this article has been viewed

Purpose: Telomerase activity is associated with cellular immortalization and is present in most human tumors but absent in normal tissues. The activity of telomerase reverse transcriptase (TERT), a catalytic telomerase subunit, correlates with telomerase activity in tumors. The objective of this study was to investigate TERT promoter methylation and its prognostic impact in gastric cancer (GC).

Patients and methods: The analysis of TERT promoter methylation was performed in tumors and corresponding normal tissues of 116 patients with GC using a highly sensitive Sequenom Epityper assay. The expression of TERT in GC tissues was measured by quantitative real-time polymerase chain reaction.

Results: The levels of TERT promoter methylation in GC samples were significantly higher than in normal adjacent tissues $(P=0.002)$. Hypermethylation of TERT promoter was associated with high T-stage $(P=0.024)$, late $\mathrm{N}$-stage $(P=0.006)$, and lymphovascular/neural invasion $(P=0.035)$, without correlation with age, sex, or histological grade. Simple linear regression analysis showed that TERT mRNA correlated positively with TERT methylation $\left(R^{2}=0.562\right.$, $P=0.001)$. Also, higher TERT mRNA expression was related to hypermethylation of TERT promoter in $\mathrm{GC}$ samples $(P=0.005)$. Univariate analysis demonstrated that $\mathrm{N}$-stage $(P=0.002)$ and TERT promoter methylation $(P=0.004)$ were predictive of overall survival. Furthermore, multivariate analysis confirmed that $\mathrm{N}$-stage $(P=0.013)$ and TERT promoter methylation $(P=0.031)$ were independent prognostic indicators for overall survival.

Conclusion: Our data suggested that hypermethylation of TERT promoter may contribute to gastric wall invasion, lymph node metastasis, lymphovascular/neural invasion, and poor prognosis in GC. GC patients with hypermethylation of TERT promoter could be eligible for close follow-up.

Keywords: telomerase reverse transcriptase, gastric cancer, methylation, prognosis, lymph node metastasis

\section{Introduction}

Gastric cancer (GC) is the third most common cancer and second leading cause of cancer-related mortality worldwide, with 989,600 new cases and 738,000 deaths per year. ${ }^{1}$ Although there have been advances in the management of GC, definitive surgical resection remains the cornerstone of curative therapy. A large proportion of patients are diagnosed with advanced and unresectable disease, and among those who present at an early stage, many suffer locoregional recurrences or distant metastases. The etiological and histological heterogeneity of GC indicates a desperate need for further insight into GC genomic characteristics, since alterations identified in GC genome might lead to the development of detailed patient stratification and individualized therapy.

Telomerase is a specialized reverse transcriptase that elongates telomeres to compensate for telomere shortening during DNA replication. ${ }^{2}$ Telomerase reverse transcriptase 
(TERT) - the catalytic unit of telomerase complex and ratelimiting determinant of telomerase activation ${ }^{3,4}$ - is expressed in $80 \%-90 \%$ human tumors including GC and most cancer cells, but not in the majority of normal tissues and somatic cells, allowing it to be a promising biomarker for various purposes, such as early diagnosis, molecular classification, prognosis assessment, and therapeutic development for cancer ${ }^{5-7}$ However, TERT has also been detected in activated lymphocytes infiltrating the tumor tissues, thereby limiting its use in the diagnosis and prognosis of cancer. ${ }^{8}$

Interestingly, TERT promoter methylation, associated with TERT expression in most telomerase-positive tumors, has been found in most cancer cells but not in activated lymphocytes with telomerase activity. ${ }^{9-15}$ Therefore, TERT methylation can be a useful cancer biomarker avoiding the interference of activated lymphocytes. In this study, we investigated the methylation pattern of TERT in GC and also elucidated the clinicopathological and prognostic significance of TERT methylation using a highly sensitive Sequenom Epityper assay. ${ }^{16,17}$

\section{Materials and methods}

\section{Patients}

Between 2007 and 2009, 116 patients with GC were treated at Shanghai Cancer Center of Fudan University. All patientderived specimens were collected and archived under protocols approved by the Institutional Review Boards of the Shanghai Cancer Center of Fudan University. Written consent for research purposes was obtained from all patients prior to surgery. All patients had undergone partial or total gastrectomy and received $\mathrm{R} 0$ resection. Patients treated with preoperative chemotherapy or radiotherapy were excluded from this study.

The study collected information on the patient sex, gastric wall invasion, lymph node metastasis, histological grade, and neural or lymphovascular invasion. The diagnosis was confirmed by at least two pathologists, and staging was based on pathological findings according to the seventh American Joint Committee on Cancer guidelines. Overall survival (OS) was calculated from the date of initial surgery to the follow-up deadline or date of death. The follow-up deadline for conducting the analysis was January 2015.

\section{Samples}

Tumor samples and their corresponding normal tissues $(\mathrm{N}=116)$ obtained during surgery were stored at $-80^{\circ} \mathrm{C}$. Genomic DNA was extracted using the QIAamp DNA Mini Kit (QIAGEN, Hilden, Germany) according to the manufacturer's procedure. Bisulfite modification of DNA was performed by EpiTect Fast DNA Bisulfite Kit according to the specified protocol (QIAGEN).

\section{Quantitative MassARRAY analysis of gene methylation status}

The Sequenom MassARRAY platform was used for the quantitative methylation analysis of TERT promoter region. The methylation status of a detected pattern was then analyzed using Epityper software version 1.0 (Sequenom Inc, San Diego, CA, USA). Polymerase chain reaction (PCR) primers were as follows: forward: 5'-GAGTTTGGATTTTTGGGAAGTTT-3', reverse: 5'TAAAACCAACATCTAATCACATCCC-3'. The amplified regions used for Sequenom are shown in Figure 1.The quantitative results were referred to as cytosine-phosphate-guanine $(\mathrm{CpG})$ units (units containing either one individual $\mathrm{CpG}$ site or multiple consecutive $\mathrm{CpG}$ sites). Methylation levels were presented as the ratio of methylated cytosines over the total number of methylated and unmethylated cytosines. TERT methylation was calculated as the mean of all $\mathrm{CpG}$ units. The cutoff of TERT methylation in tumor tissues was set at $35.5 \%$ according to a receiver operating characteristic (ROC) analysis having balanced sensitivity and specificity. TERT methylation greater or equal to $35.5 \%$ was considered as hypermethylated.

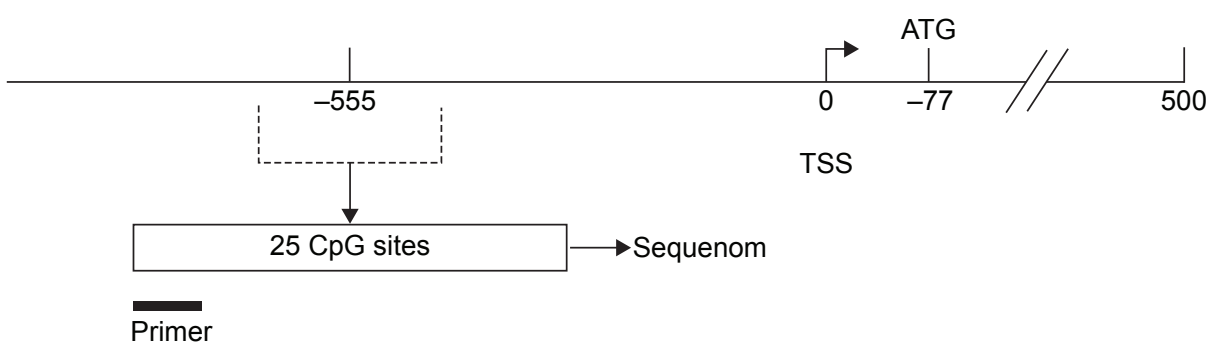

Figure I Structure diagram of the TERT promoter region.

Note: The amplified regions used for Sequenom analysis are shown as an open box.

Abbreviations: TERT, telomerase reverse transcriptase; TSS, transcription start site. 
The $\mathrm{CpG}$ units that produced data for less than $30 \%$ of samples (unreliable $\mathrm{CpG}$ units) as well as samples lacking more than $30 \%$ of their data points (unreliable samples) were discarded. ${ }^{18}$

\section{Quantitative Real-time PCR}

The expressions of TERT in 116 tumor tissue samples were confirmed by quantitative real-time PCR (qRT-PCR). Total RNA was extracted by TRIzol, and cDNAs were reverse transcribed by RevertAid ${ }^{\mathrm{TM}}$ (Thermo Fisher Scientific Inc, Vilnius, Lithuania) reverse transcriptase. Real-time PCR was carried out using the ABI PRISM 7700 Sequence Detection System (Applied Biosystems, Foster City, CA, USA). The primers for glyceraldehyde-3-phosphate dehydrogenase (GAPDH) were 5'-TGAAGGTCGGAGTCAACGG-3' (sense) and 5'-CTGGAAGATGGTGATGGGATT-3' (antisense). The primers for TERT were 5'-AAATGCGGCCCCTGTTTCT-3' (sense) and 5'-CAGTGCGTCTTGAGGAGCA-3' (antisense). The expression of the target genes was normalized to that of GAPDH. Each assay was performed in triplicate, the average was calculated, and the expression level of TERT was expressed as $2^{-\Delta \Delta \mathrm{Ct}}$, where $\Delta \mathrm{Ct}=\mathrm{Ct}(\mathrm{TERT})-\mathrm{Ct}(\mathrm{GAPDH})$.

\section{Statistical analysis}

The paired-samples t-test was used to compare methylation levels between tumor and corresponding normal tissues. The chi-square test or the Fisher's exact test was performed to assess the associations between TERT promoter methylation and clinicopathological characteristics. The association between TERT methylation and TERT mRNA expression was investigated with simple linear regression and independent-samples $t$-test. Kaplan-Meier analysis was performed to calculate OS and the log-rank test was used for estimating the significance between survival curves.
Multivariate analysis was performed with the Cox proportional hazard regression model to identify independent factors prognostic for OS. The variables affecting the prognosis in univariate analysis were added into multivariate analysis. The differences were considered statistically significant if the two-tailed $P$-value was less than 0.05 . All the statistical analysis was performed using SPSS17.0 software.

\section{Results \\ Methylation levels of individual CPG units or TERT promoter in GC tissues and corresponding normal tissues}

After removal of the unreliable data, we obtained 11 informative $\mathrm{CpG}$ units containing $22 \mathrm{CpG}$ sites, and we analyzed the methylation levels of each $\mathrm{CpG}$ unit in $\mathrm{GC}$ and normal tissues. The methylation levels at $\mathrm{CpG}_{-} 17(P=0.046)$, CpG_18.19.20.21 ( $P=0.002), \mathrm{CpG}_{2} 22(P=0.007)$, and CpG_24.25 $(P=0.003)$ were significantly higher in GC tissues than in normal tissues (Table 1).

TERT methylation was significantly higher in GC tissues than in normal tissues. The mean TERT methylation was $33.0 \% \pm 5.4 \%$ (95\% confidence interval [CI]: 32.0\%-34.0\%) in $\mathrm{GC}$ tissues and $31.4 \% \pm 3.2 \%(95 \% \mathrm{CI}: 30.9 \%-32.0 \%)$ in normal tissues $(P=0.002)$ (Figure 2$)$.

\section{TERT methylation in relation to clinicopathological characteristics}

The clinicophathological characteristics of $116 \mathrm{GC}$ patients are summarized in Table 2. The median age of the patients at surgery was 59 years (range, 29-86 years).

Based on the cutoff of $35.5 \%, 116$ GC patients were divided into hypermethylation group (TERT methylation $\geq 35.5 \%$ ) and non-hypermethylation group (TERT methylation $<35.5 \%$ ). TERT methylation status in all the GC specimens was then

Table I Methylation levels of individual CPG units in GC and corresponding normal tissues

\begin{tabular}{llll}
\hline CpG position & GC tissues, \% (mean \pm SD) & Normal tissues, \% (mean \pm SD) & P-value \\
\hline CPG_I & $23.5 \pm 11.3$ & $22.7 \pm 9.6$ & 0.406 \\
CPG_2.3.4 & $36.3 \pm 5.6$ & $37.7 \pm 6.8$ & 0.075 \\
CPG_5.6.7 & $38.5 \pm 14.3$ & $36.2 \pm 9.2$ & 0.143 \\
CPG_8.9 & $28.1 \pm 10.1$ & $28.2 \pm 7.3$ & 0.921 \\
CPG_13.14 & $14.9 \pm 4.9$ & $14.9 \pm 3.8$ & 0.911 \\
CPG_15.16 & $42.4 \pm 6.0$ & $41.4 \pm 4.9$ & 0.149 \\
CPG_17 & $62.4 \pm 27.5$ & $57.6 \pm 23.7$ & 0.046 \\
CPG_18.19.20.2I & $36.7 \pm 7.3$ & $34.6 \pm 3.7$ & 0.002 \\
CPG_22 & $29.7 \pm 7.2$ & $27.7 \pm 4.1$ & 0.007 \\
CPG_23 & $12.6 \pm 8.6$ & $11.8 \pm 7.1$ & 0.332 \\
CPG_24.25 & $36.9 \pm 6.6$ & $34.7 \pm 4.7$ & 0.003 \\
\hline
\end{tabular}

Abbreviations: GC, gastric cancer; CpG, cytosine-phosphate-guanine; SD, standard deviation. 


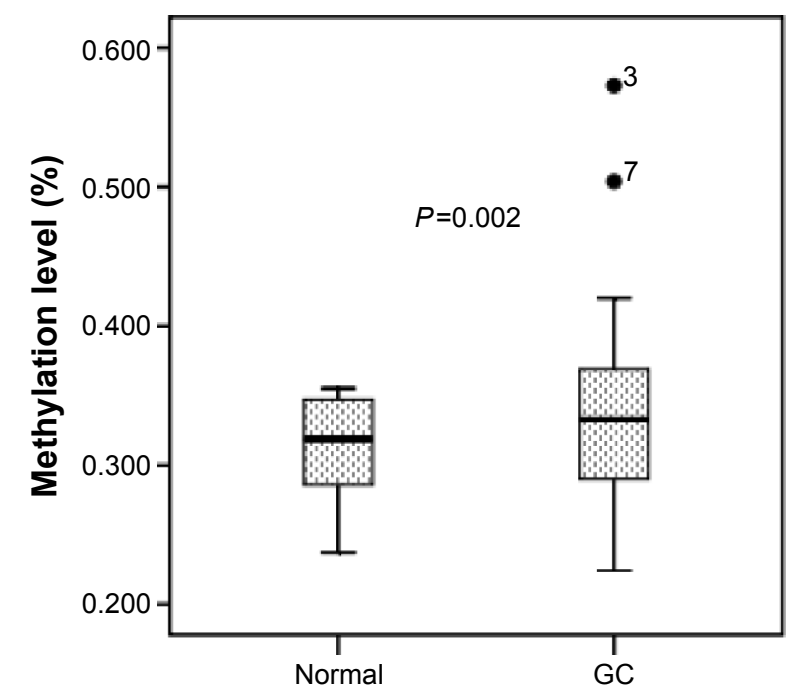

Figure 2 Median methylation levels of TERT between GC and normal tissues. Note: 3 and 7 are identifiers of two samples in the statistical analysis. Abbreviations: GC, gastric cancer; TERT, telomerase reverse transcriptase.

correlated with six widely recognized clinicopathological characteristics (Table 2). TERT methylation in GC was not associated with sex, age, and histological grade (Table 2). However, hypermethylation was more frequently observed in tumors with high T-stage (T1-2 vs T3-4, $P=0.024)$, late N stage (N0-2 vs N3, $P=0.006$ ), and lymphovascular/neural invasion (negative vs positive, $P=0.035$ ). Notably, the correlation of TERT methylation with gastric wall invasion, lymph node metastasis, and lymphovascular/neural invasion suggested a potential role of TERT methylation in increased GC metastasis.

\section{TERT methylation in relation to TERT mRNA}

The expression of TERT in GC tissues was analyzed using qRT-PCR. Simple linear regression analysis indicated that TERT mRNA expression correlated positively with TERT methylation, and the coefficient of determination $\left(R^{2}\right)$ was $0.562(P=0.001)$ (Figure 3$)$. In hypermethylated tumors, the expression levels of TERT mRNA were much higher $(2.35 \pm 0.48)$ than in non-hypermethylated tumors $(1.82 \pm 0.39$, $P=0.005$ ) (Figure 4).

\section{TERT methylation in relation to patient prognosis}

All the GC patients $(\mathrm{N}=116)$ were followed up and their median OS was calculated to be 62.2 months (95\% CI: 48.3-76.1). Using univariate analysis, we found that TERT-non-hypermethylation patients lived longer than TERT-hypermethylation patients (mean OS: 64.1 vs 44.0 months, $P=0.004$ ) (Figure 5). N0-N2 patients showed better OS than N3 patients (mean OS: 69.6 vs 47.3 months, $P=0.002$ ) (Figure 6). Other clinicopathological parameters such as age, sex, histological grade, gastric wall invasion, and lymphovascular/neural invasion did not have any impact

Table 2 Relationship between telomerase reverse transcriptase methylation and clinicopathological characteristics of II6 GC patients

\begin{tabular}{|c|c|c|c|}
\hline Characteristics & Hypermethylation, n (\%) & Non-hypermethylation, n (\%) & $P$-value \\
\hline Number of cases, $n(\%)$ & $38(32.8)$ & $78(67.2)$ & - \\
\hline \multicolumn{4}{|l|}{ Age } \\
\hline$<60$ years & $21(55.3)$ & $43(55.1)$ & \multirow[t]{2}{*}{0.989} \\
\hline$\geq 60$ years & $17(44.7)$ & $35(44.9)$ & \\
\hline \multicolumn{4}{|l|}{ Sex } \\
\hline Male & $30(78.9)$ & $59(75.6)$ & \multirow[t]{2}{*}{0.692} \\
\hline Female & $8(21.1)$ & $19(24.4)$ & \\
\hline \multicolumn{4}{|l|}{ Histological grade } \\
\hline Well/moderate & $9(23.7)$ & $17(2 \mid .8)$ & \multirow[t]{2}{*}{0.819} \\
\hline Poor & $29(76.3)$ & $6 I(78.2)$ & \\
\hline \multicolumn{4}{|l|}{ Gastric wall invasion } \\
\hline TI-2 & $3(7.9)$ & $20(25.6)$ & \multirow[t]{2}{*}{0.024} \\
\hline T3-4 & $35(92.1)$ & $58(74.4)$ & \\
\hline \multicolumn{4}{|l|}{ Lymph node metastasis } \\
\hline No-N2 & $8(21.1)$ & $37(47.4)$ & \multirow[t]{2}{*}{0.006} \\
\hline N3 & $30(78.9)$ & $4 \mathrm{l}(52.6)$ & \\
\hline \multicolumn{4}{|c|}{ Lymphovascular/neural invasion } \\
\hline Negative & $6(15.8)$ & $27(34.6)$ & \multirow[t]{2}{*}{0.035} \\
\hline Positive & $32(84.2)$ & $51(65.4)$ & \\
\hline
\end{tabular}

Abbreviation: GC, gastric cancer. 


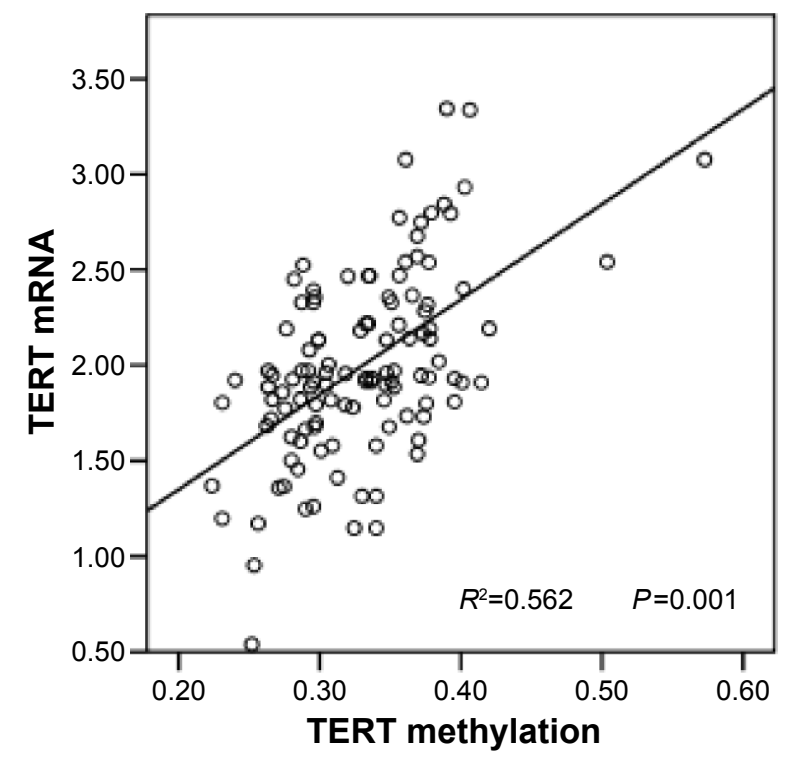

Figure 3 Regression analysis of TERT mRNA versus TERT methylation $\left(R^{2}=0.562\right)$. Abbreviations: $R^{2}$, coefficient of determination; TERT, telomerase reverse transcriptase.

on the prognosis (Table 3). Moreover, multivariate analysis using the Cox proportional hazards model showed that lymph node metastasis $(P=0.013)$ and TERT methylation $(P=0.031)$ were independent prognostic factors of GC (Table 3 ).

\section{Discussion}

In our study, we detected that TERT promoter methylation increased significantly in GC tissues compared to corresponding normal gastric tissues. Importantly, combined with clinical data, TERT methylation was associated with

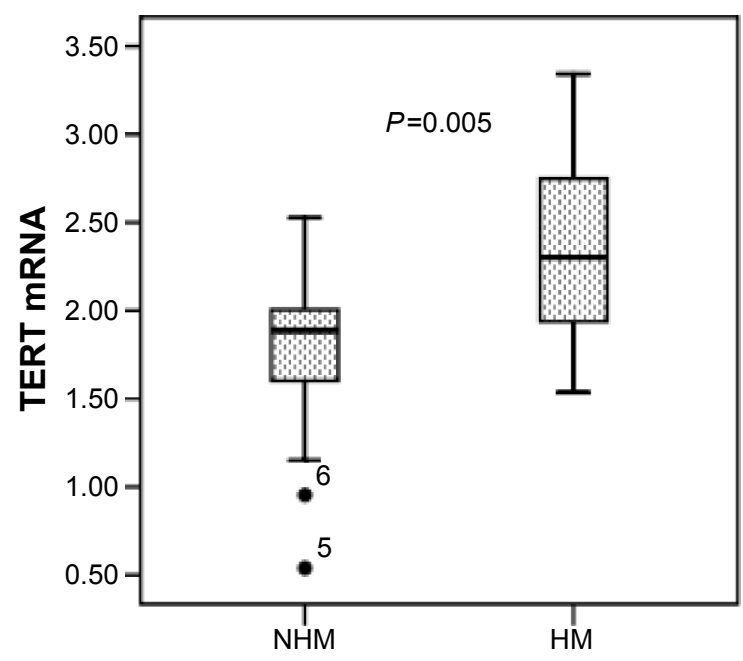

Figure 4 Median mRNA levels of TERT between HM and NHM GC tissues. Note: 5 and 6 are identifiers of two samples in the statistical analysis.

Abbreviations: GC, gastric cancer; HM, hypermethylation; NHM, nonhypermethylation; TERT, telomerase reverse transcriptase.

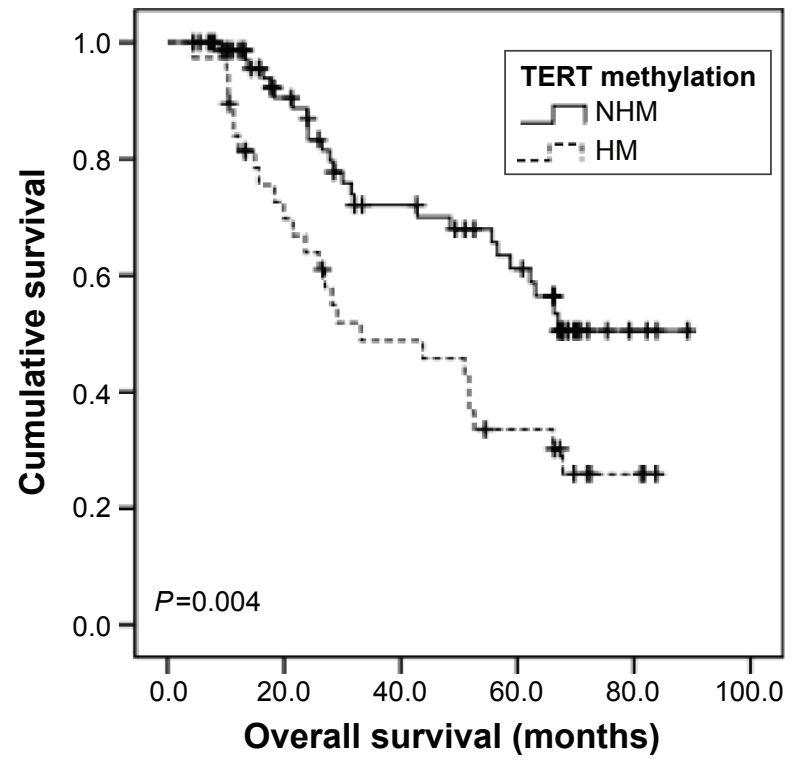

Figure 5 Comparison of survival curves based on TERT methylation. Abbreviations: HM, hypermethylation; NHM, non-hypermethylation; TERT, telomerase reverse transcriptase.

lymph node metastasis. Survival analysis showed that hypermethylation of TERT was associated with reduced OS in GC patients. TERT methylation may serve as an independent prognostic factor for GC patients. To the best of our knowledge, this is the first report demonstrating an association of TERT hypermethylation with aggressive histological features and poor prognosis in patients with GC.

Telomerase is a specialized reverse transcriptase required for the addition of telomeric repeats at the ends of eukaryotic chromosomes and is responsible for continuous cell growth.

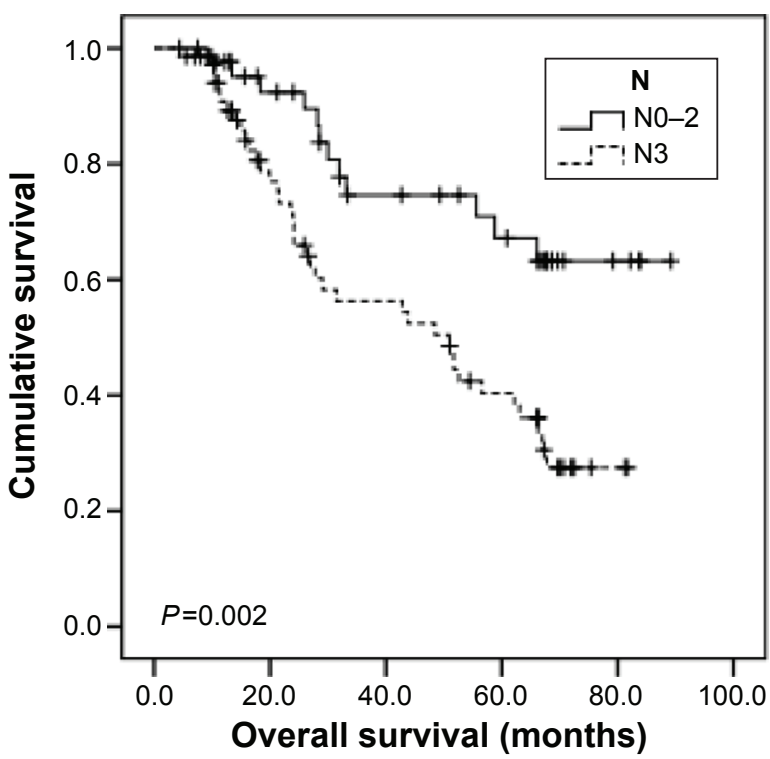

Figure 6 Comparison of survival curves based on lymph node metastasis. 
Table 3 Univariate and multivariate analysis of the prognostic significance of individual clinicopathological characteristics on overall survival

\begin{tabular}{|c|c|c|c|c|c|c|c|}
\hline \multirow[t]{2}{*}{ Characteristics } & \multirow[t]{2}{*}{$\mathbf{n}$} & \multicolumn{3}{|l|}{ Univariate analysis } & \multicolumn{3}{|c|}{ Multivariate analysis } \\
\hline & & Mean OS (months) & $95 \% \mathrm{Cl}$ & $P$-value & Hazard ratio & $95 \% \mathrm{Cl}$ & $P$-value \\
\hline \multicolumn{8}{|l|}{ Age } \\
\hline$<60$ years & 64 & 56.4 & $48.3-64.4$ & 0.580 & - & - & - \\
\hline$\geq 60$ years & 52 & 55.5 & $46.2-64.8$ & - & - & - & - \\
\hline \multicolumn{8}{|l|}{ Sex } \\
\hline Male & 89 & 59.7 & $52.2-67.1$ & 0.086 & - & - & - \\
\hline Female & 27 & 47.4 & $37.1-57.7$ & - & - & - & - \\
\hline \multicolumn{8}{|l|}{ Histological grade } \\
\hline Well/moderate & 26 & 50.9 & $40.6-61.3$ & 0.352 & - & & - \\
\hline Poor & 90 & 59.1 & $51.4-66.8$ & - & - & - & - \\
\hline \multicolumn{8}{|l|}{ Gastric wall invasion } \\
\hline TI-2 & 23 & 45.4 & $34.5-56.4$ & 0.374 & - & - & - \\
\hline T3-4 & 93 & 58.4 & $51.4-65.4$ & - & - & - & - \\
\hline \multicolumn{8}{|l|}{ Lymph node metastasis } \\
\hline N0-N2 & 45 & 69.6 & $60.3-78.9$ & 0.002 & 2.338 & $1.193-4.50 \mathrm{I}$ & 0.013 \\
\hline N3 & 71 & 47.3 & $40.1-54.4$ & - & - & - & - \\
\hline \multicolumn{8}{|c|}{ Lymphovascular/neural invasion } \\
\hline Negative & 33 & 52.8 & $44.0-61.6$ & 0.783 & - & - & - \\
\hline Positive & 83 & 56.3 & $48.7-63.9$ & - & - & - & - \\
\hline \multicolumn{8}{|l|}{ TERT methylation } \\
\hline Hypermethylation & 38 & 44.0 & $34.4-53.6$ & 0.004 & 1.966 & $1.057-3.287$ & 0.031 \\
\hline Non-hypermethylation & 78 & 64.1 & $56.5-71.8$ & - & - & - & - \\
\hline
\end{tabular}

Note: "-" represents data not available.

Abbreviations: OS, overall survival; $\mathrm{Cl}$, confidence interval; TERT, telomerase reverse transcriptase.

Progressive telomere shortening from cell division (replicative aging) blocks tumor progression. However, one of the hallmarks in advanced malignancies is continuous cell growth and this is almost universally related with the reactivation of telomerase. ${ }^{19}$ Telomerase activity is observed in approximately $90 \%$ of all malignant tumors and may predict poor prognosis in ordinary meningiomas, hepatocellular carcinomas, non-small-cell lung cancer, breast cancer, and neuroblastomas. ${ }^{19,20-25}$ TERT is a catalytic subunit of the telomerase and plays a critical role in the regulation of telomerase activity. ${ }^{3,4}$ TERT promoter was previously described as hypermethylated in many telomerase-positive tumors and cell lines. ${ }^{9,10}$ The degree of TERT methylation correlated positively with the level of telomerase activity in tumor cell lines as well as tumor tissues from different organs. ${ }^{11,26,27} \mathrm{In}$ the present study, we observed significantly reduced TERT methylation in normal gastric tissues compared to GC tissues, which is in line with a previous study based on methylationspecific PCR. ${ }^{3}$ We investigated the same region (chromosome 5: 1, 295, 557-1, 295, 772 [GRCh37/hg19]) of TERT gene that was studied previously by Catelo-Branco. ${ }^{33}$ This amplicon included $25 \mathrm{CpG}$ sites. We did not find increased methylation levels in some of the $\mathrm{CpG}$ sites of the GC tissues and this can be explained as follows: 1) some $\mathrm{CpG}$ sites in the promoter of TERT may not be the representative sites for methylation, (2) limited samples size may affect the results, and (3) limitation of the method (MassARRAY) may also affect the accuracy of the methylation levels for $\mathrm{CpG}$ sites with low methylation levels. We, therefore, detected different changes in the $25 \mathrm{CpG}$ sites. Our findings suggested that the detection of TERT methylation by Sequenom Epityper may serve as a useful tool for GC diagnosis.

In prostate cancer-prone mouse models, TERT was found to be involved in rapidly progressive disease and bone metastasis. ${ }^{28}$ Our data revealed that TERT methylation was positively associated with lymph node metastasis, gastric wall invasion, and lymphovascular/neural invasion, indicating that TERT methylation may identify an aggressive subgroup of GC. In simple linear regression model, TERT expression positively correlated with TERT methylation. Besides, we also verified that TERT expression in hypermethylated GC samples was significantly higher than in non-hypermethylated GC samples, which is in agreement with studies reporting a positive correlation between TERT methylation and mRNA expression. ${ }^{13,14}$ Conversely, Gigek et al observed no relationship between TERT methylation and TERT expression, but they found that TERT protein expression rather than TERT methylation was related to lymph node metastasis in GC. ${ }^{3}$ This difference may be due to two reasons. First, their study included population with 
heterogeneity in TNM stage. We only assessed the status of TERT methylation in GC patients without distant metastasis at diagnosis. Second, methylation-specific PCR was used in their study; however, this method has disadvantages. ${ }^{29}$ The Sequenom Epityper assay used in our study is highly accurate with regards to specific methylation sites and it enables both quantitative assessment of methylation levels and analysis of multiple methylation sites, which enables to obtain more precise data. ${ }^{17,30-32}$ Hence, we speculate that hypermethylation of TERT may be a useful biomarker in the identification of GC subsets with aggressive phenotypes.

To date, no studies have investigated TERT methylation as a prognostic factor in relation to survival in GC. We found that hypermethylation of TERT correlated with shorter OS and was an independent prognostic factor in $\mathrm{GC}$, which is consistent with the previous studies suggesting the prognostic significance of TERT methylation in carcinomas of other locations, such as brain tumors, ovarian cancer, and cervical cancer. ${ }^{33,34}$

Although the prognostic importance of TERT methylation has been supported by some evidence, a threshold defining whether the measured methylation level is hypermethylated or hypomethylated has yet to be established. Castelo-Branco et al observed the prognostic impact of TERT methylation on pediatric brain tumors using a cutoff value of $15 \% .{ }^{33}$ In our study, we conducted ROC analysis in order to precisely identify an optimal cutoff value for TERT methylation in patients with GC. For the continuous data obtained from our samples, the area under the curve (AUC) was found to be 0.601 and the cutoff value of methylation based on the Youden's index was 35.5\%. However, further studies are necessary to determine whether the cutoff of $35.5 \%$ is valid for the diagnosis and prognosis of GC.

\section{Conclusion}

To our knowledge, this is the first study to report that TERT hypermethylation may be involved in tumor progression and to provide a basis for the development of TERT methylation as a prognostic marker in GC. Determination of TERT methylation patterns may help identify high-risk GC patients, thereby enabling the optimization of treatment modalities. Nevertheless, this is a retrospective study with small sample size and innate bias in patients and methods. Further studies with large sample sizes are, therefore, essential to define the clinical implications of TERT methylation in GC.

\section{Acknowledgments}

This study was supported by a grant from the National Natural Science Foundation of China (grant number 81372432). We thank LetPub (www.letpub.com) for its linguistic assistance during the preparation of this manuscript.

\section{Disclosure}

The authors report no conflicts of interest in this work.

\section{References}

1. Jemal A, Bray F, Center MM, et al. Global cancer statistics. CA Cancer J Clin. 2011;61:69-90.

2. Lingner J, Hughes TR, Shevchenko A, et al. Reverse transcriptase motifs in the catalytic subunit of telomerase. Science. 1997;276:561-567.

3. Gigek CO, Leal MF, Silva PN, et al. hTERT methylation and expression in gastric cancer. Biomarkers. 2009;14:630-636.

4. Liu JL, Ge LY, Zhang GN. Telomerase activity and human telomerase reverse transcriptase expression in colorectal carcinoma. World J Gastroenterol. 2006;12:465-467.

5. Hiyama E, Hiyama K. Telomerase as tumor marker. Cancer Lett. 2003 194:221-233.

6. Chen $\mathrm{CH}$, Chen RJ. Prevalence of telomerase activity in human cancer J Formos Med Assoc. 2011;110:275-289.

7. Gulmann C, Lantuejoul S, Grace A, et al. Telomerase activity in proximal and distal gastric neoplastic and preneoplastic lesions using immunohistochemical detection of hTERT. Dig Liver Dis. 2005;37: 439-445.

8. Weng NP. Regulation of telomerase expression in human lymphocytes. Springer Semin Immunopathol. 2002;24:23-33.

9. Devereux TR, Horikawa I, Anna CH, et al. DNA methylation analysis of the promoter region of the human telomerase reverse transcriptase (hTERT) gene. Cancer Res. 1999;59:6087-6090.

10. Dessain SK, Yu H, Reddel RR, et al. Methylation of the human telomerase gene CpG island. Cancer Res. 2000;60:537-541.

11. Guilleret I, Yan P, Grange F, et al. Hypermethylation of the human telomerase catalytic subunit (hTERT) gene correlates with telomerase activity. Int J Cancer. 2002;101:335-341.

12. Nomoto K, Maekawa M, Sugano K, et al. Methylation status and expression of human telomerase reverse transcriptase mRNA in relation to hypermethylation of the p16 gene in colorectal cancers as analyzed by bisulfite PCR-SSCP. Jpn J Clin Oncol. 2002;32:3-8.

13. Meeran SM, Katiyar S, Katiyar SK. Berberine-induced apoptosis in human prostate cancer cells is initiated by reactive oxygen species generation. Toxicol Appl Pharmacol. 2008;229:33-43.

14. Renaud S, Loukinov D, Abdullaev Z, et al. Dual role of DNA methylation inside and outside of CTCF-binding regions in the transcriptional regulation of the telomerase hTERT gene. Nucleic Acids Res. 2007; 35:1245-1256.

15. Bougel S, Renaud S, Braunschweig R, et al. PAX5 activates the transcription of the human telomerase reverse transcriptase gene in B cells. J Pathol. 2010;220:87-96.

16. Coolen MW, Statham AL, Gardiner-Garden M, et al. Genomic profiling of $\mathrm{CpG}$ methylation and allelic specificity using quantitative highthroughput mass spectrometry: critical evaluation and improvements. Nucleic Acids Res. 2007;35:e119.

17. Ehrich M, Nelson MR, Stanssens P, et al. Quantitative high throughput analysis of DNA methylation patterns by base specific cleavage and mass spectrometry. Proc Natl Acad Sci U S A. 2005;102:15785-15790.

18. Ollikainen M, Smith KR, Joo EJ, et al. DNA methylation analysis of multiple tissues from newborn twins reveals both genetic and intrauterine components to variation in the human neonatal epigenome. Hum Mol Genet. 2010;19:4176-4188.

19. Kim NW, Pietyszek MA, Prowse KR, et al. Specific association of human telomerase activity with immortal cells and cancer. Science. 1994;266:2011-2015

20. Langford LA, Piatyszek MA, Xu RS, et al. Telomerase activity in ordinary meningiomas predicts poor outcome. Human Pathol. 1997; 28:416-420. 
21. Oh BK, Kim H, Park YN, et al. High telomerase activity and long telomeres in advanced hepatocellular carcinomas with poor prognosis. Lab Invest. 2008;88:144-152.

22. Chen KY, Lee LN, Yu CJ, et al. Elevation of telomerase activity positively correlates to poor prognosis of patients with non-small cell lung cancer. Cancer Lett. 2006;240:148-156.

23. González-Quevedo R, Iniesta P, Morán A, et al. Cooperative role of telomerase activity and p16 expression in the prognosis of non-smallcell lung cancer. J Clin Oncol. 2002;20:254-262.

24. Carey LA, Kim NW, Goodman S, et al. Telomerase activity and prognosis in primary breast cancers. J Clin Oncol. 1999;17:3075-3081.

25. Poremba C, Willenbring H, Hero B, et al. Telomerase activity distinguishes between neuroblastomas with good and poor prognosis. Ann Oncol. 1999;10:715-721.

26. Kumari A, Srinivasan R, Vasishta RK, et al. Positive regulation of human telomerase reverse transcriptase gene expression and telomerase activity by DNA methylation in pancreatic cancer. Ann Surg Oncol. 2009;16: 1051-1059.

27. Valls-Bautista C, Bougel S, Piñol-Felis C, et al. hTERT methylation is necessary but not sufficient for telomerase activity in colorectal cells. Oncol Lett. 2011;2:1257-1260.
28. Ding Z, Wu CJ, Jaskelioff M, et al. Telomerase reactivation following telomere dysfunction yields murine prostate tumors with bone metastases. Cell. 2012;148:896-907.

29. Klose RJ, Bird AP. Genomic DNA methylation: the mark and its mediators. Trends Biochem Sci. 2006;31:89-97.

30. Yu J, Tao Q, Cheng YY, et al. Promoter methylation of the Wnt/betacatenin signaling antagonist Dkk-3 is associated with poor survival in gastric cancer. Cancer. 2009;115:49-60.

31. Stanssens P, Zabeau M, Meersseman G, et al. High-throughput MALDITOF discovery of genomic sequence polymorphisms. Genome Res. 2004;14:126-133.

32. Bellido ML, Radpour R, Lapaire O, et al. MALDI-TOF mass array analysis of RASSF1A and SERPINB5 methylation patterns in human placenta and plasma. Biol Reprod. 2010;82:745-750.

33. Castelo-Branco P, Choufani S, Mack S, et al. Methylation of the TERT promoter and risk stratification of childhood brain tumours: an integrative genomic and molecular study. Lancet Oncol. 2013;14:534-542.

34. Widschwendter A, Müller HM, Hubalek MM, et al. Methylation status and expression of human telomerase reverse transcriptase in ovarian and cervical cancer. Gynecol Oncol. 2004;93:407-416.
OncoTargets and Therapy

\section{Publish your work in this journal}

OncoTargets and Therapy is an international, peer-reviewed, open access journal focusing on the pathological basis of all cancers, potential targets for therapy and treatment protocols employed to improve the management of cancer patients. The journal also focuses on the impact of management programs and new therapeutic agents and protocols on

\section{Dovepress}

patient perspectives such as quality of life, adherence and satisfaction The manuscript management system is completely online and includes a very quick and fair peer-review system, which is all easy to use. Visit http://www.dovepress.com/testimonials.php to read real quotes from published authors. 